\title{
Pulmonary Recruitment Manoeuvre-A Novel Approach For Postoperative Pain Reduction In Laparoscopic Surgery
}

\author{
Ritik Bansal ${ }^{1}$,Rajesh Ballal ${ }^{2}$,Ananda Bangera ${ }^{3}$ \\ ${ }^{1}$ Resident In General Surgery, ${ }^{2}$ Professor Of Surgery, K.S.Hegde Medical Academy, ${ }^{3}$ Professor Of Anaesthesia, \\ K.S.Hegde Medical Academy. \\ Vaishali Colony, Garh Road Meerut(U.P.) - 250001india
}

\begin{abstract}
Introduction: Shoulder tip pain and abdominal pain following laparoscopic procedures are well recognized and established causes of postoperative morbidities The etiology of this pain being multifactorial,includes volume of residual gas, type of gas used, intraperitoneal pressures and temperature of insufflated gas.

Methodology: Study is an interventional case control study. Total 68 patients were enrolled in the study, 34 being in each group.Control group patients' pneumoperitoneum was evacuated passively at the end of procedure.Study group patients were placed in Trendelenburg position (30 degrees) and a pulmonary recruitment manoeuvre was utilized comprising of two mechanical inflations to a maximum pressure of $60 \mathrm{cmH} 2 \mathrm{O}$,each lasting for 5seconds with valves of operative ports fully open. Pain scores were asessed at $6,12,24$ and 48 hour by use of validated visual analogue scale(VAS).

Results: Postoperative pain scores at $6^{\text {th }}, 12^{\text {th }}, 24$ and $48^{\text {th }}$ hours for both abdominal and shoulder tip pain were found to be significantly low (with $p$ value of 0.00) in study group when compared with those of control group.Also there was no significant difference noted in duration of surgery when compared between control and study group.
\end{abstract}

Conclusion: With this encouraging incidence of pain reduction this manoeuvre should be incorporated in other intra-abdominal laparoscopic surgeries and results needs to be evaluated.

Keywords: pulmonary recruitment manoeuvre, abdominal pain, shoulder tip pain, duration of surgery, drain placement, VAS pain score

\section{Introduction}

The field of minimally invasive surgery has experienced an explosive growth in past three decades. Though the art of surgery has gone through a complete evolutionary process due to antisepsis, antibiotics, anaesthesia and concept ofaseptic surgery spread over centuries, the field of laparoscopic surgery has witnessed major changes only in the recent past. Post laparoscopic procedural pain namely shoulder tip and abdominal pain are well recognized and established causes of postoperative morbidity ${ }^{1,2}$. The aetiology for this postoperative pain is multifactorial and includes the volume of residual gas, intra-peritoneal pressures resulting from establishment of the pneumoperitoneum, type of gas used and temperature of the insufflated gas $^{2,3,4,5}$. Though the mechanism is not well understood, the theory proposed regarding shoulder pain is carbon dioxide retention within the abdomen, subsequently irritating the phrenic nerve and causing referred pain in the $\mathrm{C} 4$ dermatome. Moreover, residual carbon dioxide that is trapped between the liver and the right diaphragm, irritating the diaphragm, also causes upper abdominal pain. All relate to the morbidity after laparoscopic surgery ${ }^{6,7}$. Mechanisms described to reduce pain intensity include a reduction in pneumoperitoneal pressure ${ }^{8}$, infiltration of wounds with local anaesthetic ${ }^{9,10}$,administration of non-steroidal anti-inflammatory drugs (NSAIDs) ${ }^{11,12,13}$, use of intra-peritoneal local anaesthetic agents ${ }^{14,15,16}$ and removal of gases ${ }^{17,18,19}$. Removal of residual gas at the end of the procedure can be achieved by various techniques like manual compression of abdomen, intra-peritoneal normal saline infusion, active evacuation of gas by suction and pulmonary recruitment manoeuvre. Pulmonary recruitment manoeuvre (PRM) has been proposed to reduce shoulder and upper abdominal pain as it assists the expulsion of abdominal residual carbon dioxide by active intervention of mechanically increasing the intra-thoracic pressure therefore resulting in rise in intra-peritoneal pressure. This secondary rise in intra-peritoneal pressure acts as a driving force which facilitates the removal of residual pneumoperitoneum immediately after operation.

II. Aim

To compare the efficacy of a simple pulmonary recruitment manoeuvre to reduce pain, in comparison to conventionally practiced passive evacuation of residual carbon dioxide in laparoscopic surgeries. 


\section{Methodology}

It is a non-randomized interventional study involving Patients who underwent elective laparoscopic cholecystectomy in Justice K.S. Hegde Charitable Hospital, a unit of KS Hedge Medical Academy, NITTE University during November 2014 To June 2016.A total 68 patients were included in the study, 34 patients being in each group. All patients who underwent elective laparoscopic cholecystectomy with American Society Of Anesthesiologists (ASA) physical status grade I or grade II were included in the study. Whereas patients with ASA grade III or above,age less than 18 years,in cases where laparoscopic surgeries converted to open surgeries,pregnant females,patients undergoing SILS instead of conventional technique of using 3-4 ports for laparoscopic surgeries and patients in which use of rescue analgesic will be needed were excluded from the study. In control group, i.e. PM (Passive Mechanism) Group residual carbon dioxide pneumoperitoneum was evacuated passively at the end of procedure by opening operative ports to allow the abdomen to decompress.In study group, i.e. PRM (Pulmonary Recruitment Manoeuvre) Group in addition to the measures taken for control group, additionally patient was placed in Trendelenburg position (30 degrees) and a pulmonary recruitment manoeuvre was utilized by the anaesthesiologist, comprising of two mechanical inflations to a maximum pressure of $60 \mathrm{cmH} 2 \mathrm{O}$ and each positive pressure inflation lasted for 5 seconds with valves of operative ports fully open.

Pain scores were assessed at 6,12,24 and 48 hours by use of validated visual analogue scale $($ VAS). $0=$ no pain, $10=$ worst conceivable pain.Injection Paracetamol $1 \mathrm{~g}$ for patients weighing $>50 \mathrm{~kg}$ and $15 \mathrm{mg} / \mathrm{kg}$ for patient weighing $<50 \mathrm{~kg}$ TID were prescribed as analgesic agent of choice for all the cases that were included in the study.Injection Tramadol was reserved as rescue analgesic.

\section{Following parameters were assessed}

Post operative abdominal pain based on VAS score.

Post operative shoulder tip pain based on VAS score.

\section{Statistical Analysis}

Statistical analysis was done using grading of pain and chi square test to see the association of independent variables on dependent variable (Pain). Man- Whitney's test was done to compare between two groups about the difference in non parametric outcome and t-test for parametric outcome. Correlation coefficient was looked for ASA grading and outcome variable.

\section{Results}

A total of 64 patients were enrolled in the study, 34 being allotted to each group as per purposive method of distribution (1:1). Population under each group was matched of age, sex and BMI to avoid bias while evaluating the parameters under study. 26 patients of which 15(44.1\%) from PRM and 11(32.4\%) from PM group the time taken for completion of surgery was less than 1 hour $30 \mathrm{~min}$. In remaining 42 patients time taken for completion of procedure was more than 1 hour and 30min.Of these 42 patients 19(55.9\%) were in PRM and $23(67.6 \%)$ were in PM group. On calculating the $\mathrm{p}$ value in order to compare the additional time consumed in patients who underwent intervention it was found to be non-significant(p value-0.318), thereby time difference to complete the procedure wasn't significantly different among the two groups.

Among 68 patients of the cohort in 38 patients intra-abdominal drain was placed at the end of the procedure. Of these 30 patients, 17 (i.e. 50\% of total PRM group patients) were in PRM group and 21(i.e. 61.8\% of total PM group patients) were in PM group. On comparing and calculating the $\mathrm{P}$ value for both the groups with respect to patients with drain it was found to be non significant ( $\mathrm{p}$ value 0.329). The importance of this calculation forms the basis for proving that presence or absence of drain wasn't a confounding factor when the pain scores were compared between PRM and PM group patients.

\section{VAS Score for Abdominal Pain}

Abdominal pain as per the VAS score was evaluated at 6th ,12th, 24th and $48^{\text {th }}$ hours. On comparing the results in PRM and PM group the score was found to be much less in the patients undergoing manoeuvre. (Figure1;Figure 2;Table1). 


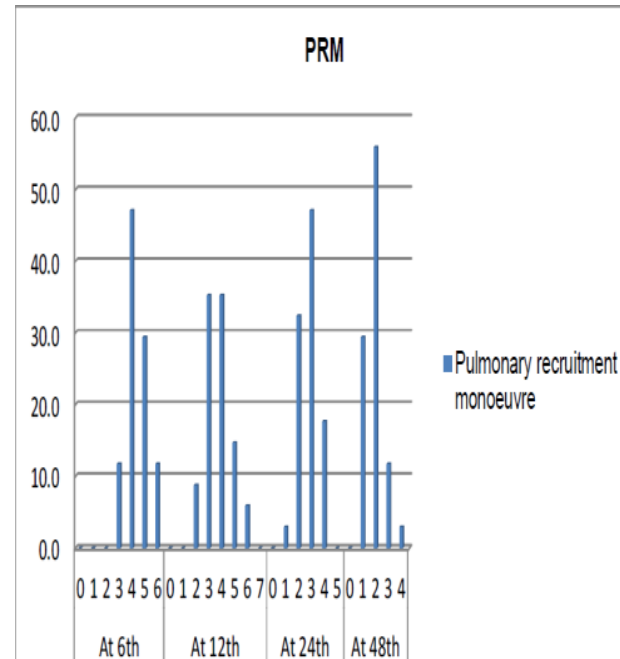

Figure 1
PM

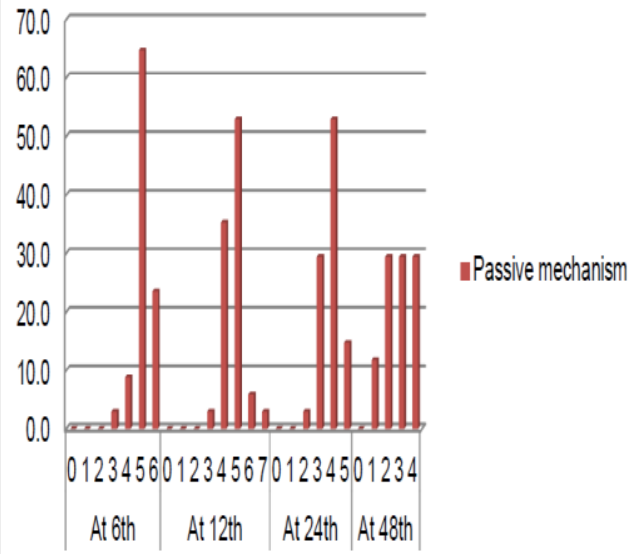

Figure 2

\begin{tabular}{|c|c|c|c|c|c|c|c|c|c|}
\hline & & \multicolumn{2}{|c|}{ PRM } & \multicolumn{2}{|c|}{ PM } & \multirow[b]{2}{*}{$\begin{array}{c}\text { Median(IQR) } \\
\text { - Test }\end{array}$} & \multirow[b]{2}{*}{$\begin{array}{l}\text { Median(IQR) - } \\
\text { Controls }\end{array}$} & \multicolumn{2}{|c|}{ Mannwhitney test } \\
\hline & & Freq & $\%$ & Freq & $\%$ & & & $\mathbf{Z}$ value & $\mathrm{p}$ value \\
\hline \multirow[t]{8}{*}{ At 6th } & 0 & 0 & $.0 \%$ & 0 & $.0 \%$ & $4(4-5)$ & $5(5-5.25)$ & 3.50 & .000 \\
\hline & 1 & 0 & $.0 \%$ & 0 & $.0 \%$ & & & & HS \\
\hline & 2 & 0 & $.0 \%$ & 0 & $.0 \%$ & & & & \\
\hline & 3 & 4 & $11.8 \%$ & 1 & $2.9 \%$ & & & & \\
\hline & 4 & 16 & $47.1 \%$ & 3 & $8.8 \%$ & & & & \\
\hline & 5 & 10 & $29.4 \%$ & 22 & $64.7 \%$ & & & & \\
\hline & 6 & 4 & $11.8 \%$ & 8 & $23.5 \%$ & & & & \\
\hline & Total & 34 & $100.0 \%$ & 34 & $100.0 \%$ & & & & \\
\hline \multirow[t]{7}{*}{$\begin{array}{l}\text { At } \\
\text { 12th }\end{array}$} & 0 & 0 & $.0 \%$ & 0 & $.0 \%$ & $4(3-4)$ & $5(4-5)$ & 4.04 & .000 \\
\hline & 1 & 0 & $.0 \%$ & 0 & $.0 \%$ & & & & HS \\
\hline & 2 & 3 & $8.8 \%$ & 0 & $.0 \%$ & & & & \\
\hline & 3 & 12 & $35.3 \%$ & 1 & $2.9 \%$ & & & & \\
\hline & 4 & 12 & $35.3 \%$ & 12 & $35.3 \%$ & & & & \\
\hline & 5 & 5 & $14.7 \%$ & 18 & $52.9 \%$ & & & & \\
\hline & 6 & 2 & $5.9 \%$ & 2 & $5.9 \%$ & & & & \\
\hline
\end{tabular}

\begin{tabular}{|l|c|c|c|c|c|c|c|c|c|}
\hline & 7 & 0 & $.0 \%$ & 1 & $2.9 \%$ & & & & \\
\hline & Total & 34 & $100.0 \%$ & 34 & $100.0 \%$ & & & & \\
\hline $\begin{array}{l}\text { At } \\
24 \text { th }\end{array}$ & 0 & 0 & $.0 \%$ & 0 & $.0 \%$ & $3(2-3)$ & $4(3-4)$ & 4.62 & .000 \\
\hline & 1 & 1 & $2.9 \%$ & 0 & $.0 \%$ & & & & HS \\
\hline & 2 & 11 & $32.4 \%$ & 1 & $2.9 \%$ & & & & \\
\hline & 3 & 16 & $47.1 \%$ & 10 & $29.4 \%$ & & & & \\
\hline & 4 & 6 & $17.6 \%$ & 18 & $52.9 \%$ & & & & \\
\hline & 5 & 0 & $.0 \%$ & 5 & $14.7 \%$ & & & & \\
\hline & Total & 34 & $100.0 \%$ & 34 & $100.0 \%$ & & & & \\
\hline At & 0 & 0 & $.0 \%$ & 0 & $.0 \%$ & $2(1-2)$ & $3(2-4)$ & 3.64 & .000 \\
\hline & 0 & 10 & $29.4 \%$ & 4 & $11.8 \%$ & & & & HS \\
\hline & 2 & 19 & $55.9 \%$ & 10 & $29.4 \%$ & & & & \\
\hline & 3 & 4 & $11.8 \%$ & 10 & $29.4 \%$ & & & & \\
\hline & 4 & 1 & $2.9 \%$ & 10 & $29.4 \%$ & & & & \\
\hline & Total & 34 & $100.0 \%$ & 34 & $100.0 \%$ & & & & \\
\hline
\end{tabular}

Table 1 
On calculating the $\mathrm{p}$ value and comparing the results between the two group patients, pain scores were found to significantly low at all four readings. Thereby,emphasizing the advantage of manoeuvre in reducing both short and long duration pain.

\section{VAS Score for Shoulder Pain}

Shoulder tip pain as per the VAS score was evaluated at 6th,12th, 24th and $48^{\text {th }}$ hours. On comparing the results in PRM and PM group the results were found to be similar to those of abdominal pain results. (Figure3;Figure 4;Table2).

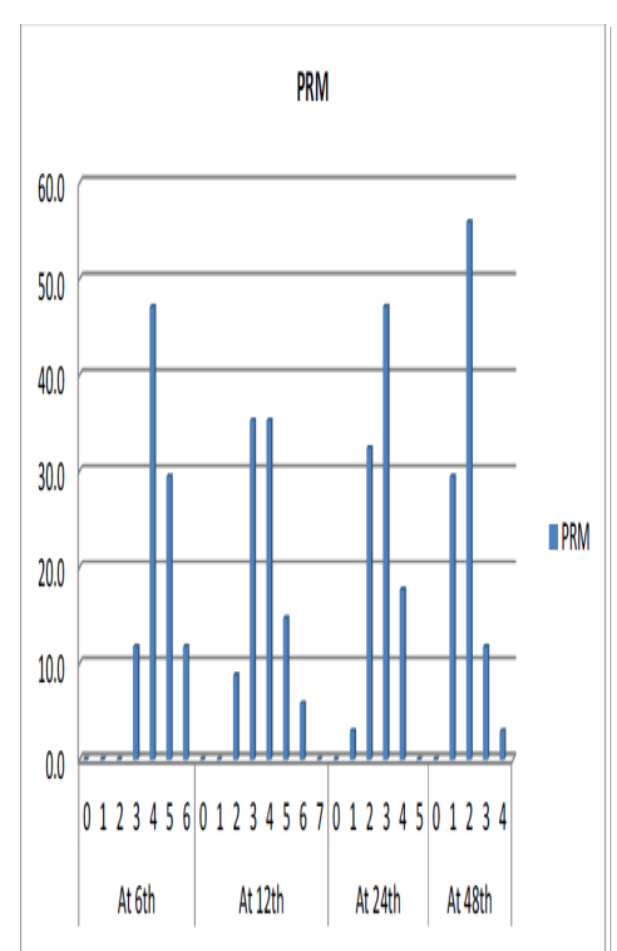

Figure 3

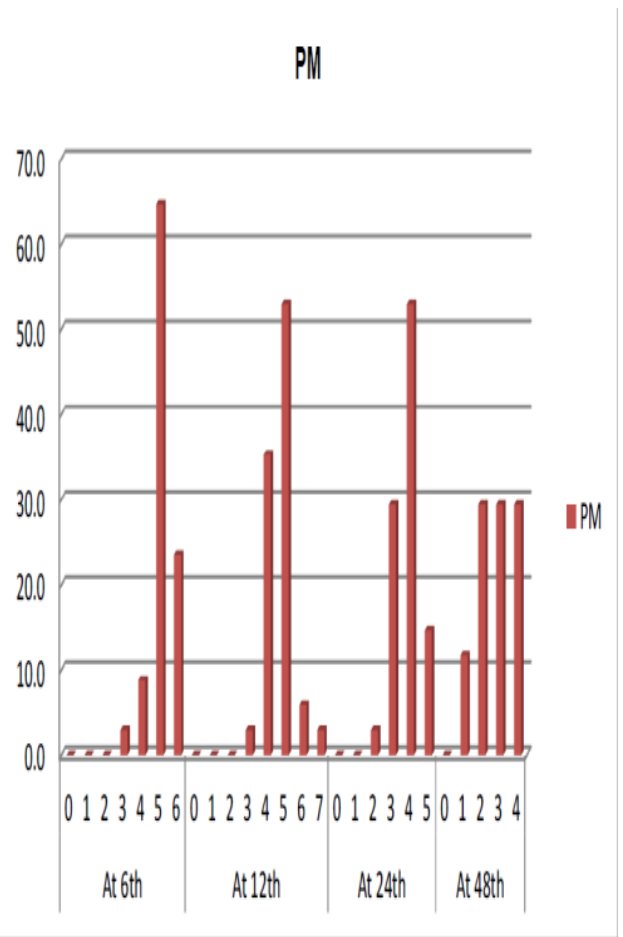

Figure 4

\begin{tabular}{|c|c|c|c|c|c|c|c|c|c|}
\hline & & \multicolumn{2}{|c|}{ PRM } & \multicolumn{2}{|c|}{ PM } & \multirow[b]{2}{*}{$\begin{array}{c}\text { Median(IQR) } \\
\text { - Test }\end{array}$} & \multirow[b]{2}{*}{$\begin{array}{c}\text { Median(IQR) } \\
\text { Controls }\end{array}$} & \multicolumn{2}{|c|}{ Mannwhitney test } \\
\hline & & Freq & $\%$ & Freq & $\%$ & & & $\boldsymbol{Z}$ value & $p$ value \\
\hline \multirow[t]{8}{*}{ At 6th } & 0 & 23 & $67.6 \%$ & 10 & $29.4 \%$ & $0(0-1)$ & $1.5(0-2)$ & 4.03 & .000 \\
\hline & 1 & 10 & $29.4 \%$ & 7 & $20.6 \%$ & & & & HS \\
\hline & 2 & 1 & $2.9 \%$ & 12 & $35.3 \%$ & & & & \\
\hline & 3 & 0 & $.0 \%$ & 4 & $11.8 \%$ & & & & \\
\hline & 4 & 0 & $.0 \%$ & 1 & $2.9 \%$ & & & & \\
\hline & 5 & 0 & $.0 \%$ & 0 & $.0 \%$ & & & & \\
\hline & 6 & 0 & $.0 \%$ & 0 & $.0 \%$ & & & & \\
\hline & Total & 34 & $100.0 \%$ & 34 & $100.0 \%$ & & & & \\
\hline \multirow[t]{6}{*}{$\begin{array}{l}\text { At } \\
12 \text { th }\end{array}$} & 0 & 25 & $73.5 \%$ & 11 & $32.4 \%$ & $0(0-1)$ & $2(0-2)$ & 4.02 & .000 \\
\hline & 1 & 7 & $20.6 \%$ & 5 & $14.7 \%$ & & & & HS \\
\hline & 2 & 2 & $5.9 \%$ & 16 & $47.1 \%$ & & & & \\
\hline & 3 & 0 & $.0 \%$ & 1 & $2.9 \%$ & & & & \\
\hline & 4 & 0 & $.0 \%$ & 1 & $2.9 \%$ & & & & \\
\hline & 5 & 0 & $.0 \%$ & 0 & $.0 \%$ & & & & \\
\hline
\end{tabular}




\begin{tabular}{|c|c|c|c|c|c|c|c|c|c|}
\hline & 6 & 0 & $.0 \%$ & 0 & $.0 \%$ & & & & \\
\hline & 7 & 0 & $.0 \%$ & 0 & $.0 \%$ & & & & \\
\hline & Iotal & 34 & $100.0 \%$ & 34 & $100.0 \%$ & & & & \\
\hline $\begin{array}{l}\text { At } \\
\text { 24th }\end{array}$ & 0 & 34 & $100.0 \%$ & 20 & $58.8 \%$ & $0(0-0)$ & $0(0-1)$ & 4.14 & .000 \\
\hline & 1 & 0 & $.0 \%$ & 8 & $23.5 \%$ & & & & HS \\
\hline & 2 & 0 & $.0 \%$ & 6 & $17.6 \%$ & & & & \\
\hline & 3 & 0 & $.0 \%$ & 0 & $.0 \%$ & & & & \\
\hline & 4 & 0 & $.0 \%$ & 0 & $.0 \%$ & & & & \\
\hline & 5 & 0 & $.0 \%$ & 0 & $.0 \%$ & & & & \\
\hline & Total & 34 & $100.0 \%$ & 34 & $100.0 \%$ & & & & \\
\hline $\begin{array}{l}\text { At } \\
\text { 48th }\end{array}$ & 0 & 34 & $100.0 \%$ & 29 & $85.3 \%$ & $0(0-0)$ & $0(0-0)$ & 2.31 & .021 \\
\hline & 1 & 0 & $.0 \%$ & 5 & $14.7 \%$ & & & & sig \\
\hline & 2 & 0 & $.0 \%$ & 0 & $.0 \%$ & & & & \\
\hline & 3 & 0 & $.0 \%$ & 0 & $.0 \%$ & & & & \\
\hline & 4 & 0 & $.0 \%$ & 0 & $.0 \%$ & & & & \\
\hline & Total & 34 & $100.0 \%$ & 34 & $100.0 \%$ & & & & \\
\hline
\end{tabular}

\section{Table 2}

Similar to abdominal pain the pain scores were found to be significantly different in PRM and PM group with significant $\mathrm{p}$ value of $0.00,0.00,0.00$ and 0.021 at 6 th, 12th, 24th and 48th hours respectively. Hence signifying manoeuvre is effective in reducing both short and long duration shoulder tip pain in patients undergoing laparoscopic cholecystectomy.

\section{Conclusion}

In light of the above results routine use of this intervention should be considered at the end of laparoscopic cholecystecomy surgeries.With this encouraging incidence of pain reduction this manoeuvre should be incorporated in other intraabdominal laparoscopic surgeries and results needs to be evaluated.

Ethical approval: "All procedures performed in studies involving human participants were in accordance with the ethical standards of the institutional ethics committee and with the 1964 Helsinki declaration and its later amendments or comparable ethical standards."

Informed consent: Informed consent was obtained from all the participants included in the study

\section{Refrences}

[1]. Mouton WG, Bessell JR, Otten KT, Maddern GJ. Pain after laparoscopy.

[2]. Surg Endosc 1999; 13: 445-448.

[3]. Wills VL, Hunt DR. Pain after laparoscopic cholecystectomy. Br J Surg 2000;87: 273-284.

[4]. Aitola P, Airo I, Kaukinen S, Ylitalo P. Comparison of N2O and CO2 pneumoperitoneums during laparoscopic cholecystectomy with special reference to postoperative pain. Surg Laparosc Endosc 1998; 8: 140-144.

[5]. Jackson SA, Laurence AS, Hill JC. Does post-laparoscopy pain relate to

[6]. residual carbon dioxide? Anaesthesia 1996; 51: 485-487.

[7]. Wallace DH, Serpell MG, Baxter JN, O’Dwyer PJ. Randomized trial of

[8]. different insufflation pressures for laparoscopic cholecystectomy. Br J Surg

[9]. $1997 ; 84: 455-458$

[10]. Gurusamy KS, Vaughan J, Rossi M, Davidson BR. Fewer-than-four ports versus four ports for laparoscopic cholecystectomy. Cochrane Database Sys Rev 2014;2:Cd007109.

[11]. Khanna A, Sezen E, Barlow A, Rayt H, Finch JG. Randomized clinical trial

[12]. of a simple pulmonary recruitment manoeuvre to reduce pain after

[13]. laparoscopy. Br J Surg 2013;100(10):1290-4.

[14]. Sandhu T, Yamada S, Ariyakachon V, Chakrabandhu T, Chongruksut W,

[15]. Ko-iam W. Low-pressure pneumoperitoneum versus standard pneumoperitoneum in laparoscopic cholecystectomy, a prospective randomized clinical trial. Surg Endosc 2009; 23: 1044-1047.

[16]. Pavlidis TE, Atmatzidis KS, Papaziogas BT, Makris JG, Lazaridis CN, Papaziogas TB. The effect of preincisional periportal infiltration with ropivacaine in pain relief after laparoscopic procedures: a prospective, randomized controlled trial. JSLS 2003; 7: 305-310.

[17]. Papagiannopoulou P, Argiriadou H, Georgiou M, Papaziogas B, Sfyra E,

[18]. Kanakoudis F. Preincisional local infiltration of levobupivacaine vs ropivacaine for pain control after laparoscopic cholecystectomy. Surg Endosc 2003; 17: 1961-1964.

[19]. Abdulla S, Eckhardt R, Netter U, Abdulla W. A randomized, double-blind, controlled trial on non-opioid analgesics and opioid consumption for postoperative pain relief after laparoscopic cholecystectomy. Acta Anaesthesiol Belg 2012; 63: 43-50.

[20]. Gan TJ, Joshi GP, Zhao SZ, Hanna DB, Cheung RY, Chen C. Presurgical intravenous parecoxib sodium and follow-up oral valdecoxib for pain management after laparoscopic cholecystectomy surgery reduces opioid requirements and opioid-related adverse effects. Acta Anaesthesiol Scand 2004; 48: 1194-1207.

[21]. Puura A, Puolakka P, Rorarius M, Salmelin R, Lindgren L. Etoricoxib pre 
[22]. medication for post-operative pain after laparoscopic cholecystectomy. Acta

[23]. Anaesthesiol Scand 2006; 50: 688-693.

[24]. Dreher JK, Nemeth D, Limb R. Pain relief following day case laparoscopic tubal ligation with intra-peritoneal ropivacaine: a randomised double blind control study. Aust N Z J Obstet Gynaecol 2000; 40: 434-437.

[25]. Hernández-Palazón J, Tortosa JA, Nuñ o de la Rosa V, Gim'enez-Viudes J, Ram'irez G, Robles R. Intraperitoneal application of bupivacaine plus morphine for pain relief after laparoscopic cholecystectomy. Eur J Anaesthesiol 2003; 20:891-896.

[26]. Park YH, Kang H, Woo YC, Park SG, Baek CW, Jung YH et al. The effect of intraperitoneal ropivacaine on pain after laparoscopic colectomy: a prospective randomized controlled trial. J Surg Res 2011; 171: 94-100.

[27]. Jorgensen JO, Gillies RB, Hunt DR, Caplehorn JR, Lumley T. A simple and

[28]. effective way to reduce postoperative pain after laparoscopic cholecystectomy. Aust N Z J Surg 1995; 65: 466-469.

[29]. Nursal TZ, Yildirim S, Tarim A, Noyan T, Poyraz P, Tuna N et al. Effect of drainage on postoperative nausea, vomiting, and pain after laparoscopic cholecystectomy. Langenbecks Arch Surg 2003; 388: 95-100.

[30]. Tsai HW, Chen YJ, Ho CM, Hseu SS, Chao KC, Tsai SK et al. Maneuvers to decrease laparoscopy-induced shoulder and upper abdominal pain: a

[31]. randomized controlled study.Arch Surg 2011; 146: 1360-1366 